\title{
Chiasmal apoplexy: haemorrhage from a cavernous malformation in the optic chiasm
}

\author{
LUCA REGLI,* NICOLAS DE TRIBOLET, * FRANCO REGLI, ** \\ JULIEN BOGOUSSLAVSKY** \\ From the Departments of Neurosurgery* and Neurology**, University Hospital, Lausanne, Switzerland
}

SUMMARY We present a patient who experienced sudden onset of orbital headache, visual loss and bitemporal visual field defect. MRI of the optic chiasm suggested a diagnosis of haemorrhage and hence a vascular malformation. Pterional craniotomy revealed an intrachiasmatic haematoma with a cavernous angioma. The malformation was totally excised and vision improved after surgery. The syndrome of chiasmal apoplexy is discussed.

Visual field defects due to chiasmal compression from a tumour usually progress slowly. An acute syndrome may be due to ischaemic, haemorrhagic or demyeliniating disease.

"Chiasmal apoplexy" is essentially associated with haemorrhage in the chiasm itself and is typically of sudden onset. We report a case of spontaneous haematoma in the optic chiasm from a cavernous malformation which could be suspected on magnetic resonance imaging (MRI). The clinical and radiological features of 16 cases reported previously are discussed, only our patient had MRI.

\section{Case report}

A 28 year old healthy woman suddenly complained of right sided supra- and retro-orbital headache, blurred vision on the right eye and a visual defect on both temporal fields. This was the first episode and she had no other complaints.

\section{Examination}

Physical examination was entirely normal four hours after onset, except for her vision. Visual acuity was $1 / 60$ in the right eye and $20 / 20$ in the left eye. Her visual field revealed a dense right temporal hemianopia and a relative left temporal hemianopia (fig 1). The optic fundi were normal. There was

Correspondence to: Dr $\mathrm{N}$ de Tribolet, Department of Neurosurgery, University Hospital, Lausanne, Switzerland

Received 23 December 1988.

Accepted 11 April 1989 no pupillary defect. Computerised tomography showed a high-density, poorly enhanced mass in the anterior part of the right optochiasmal cistern (fig 2). The carotid angiography was normal. MRI, performed three days after onset, showed enlargement of the chiasm on the right side by an intrachiasmal lesion with a mixed hypo- and a slight hyperintense signal, when compared with grey matter, on mildly $\mathrm{Tl}$ and proton-weighted images (figs 3 and 4).

\section{Operation}

A diagnosis of chiasmal apoplexy was made and a right sided pterional craniotomy was performed to explore the chiasm. The anterior and right paramedian parts of the chiasm were distended by haemorrhage and protruded into the optochiasmal cistern. The pia-mater was incised on the chiasm and a characteristic "mulberry-like" vascular malformation was apparent. A dissection plane separating the haematoma and the surrounding gliosis enabled a complete excision of the malformation. It measured six $\mathrm{mm}$ in diameter. A histological examination showed a typical cavernous angioma (figure 5).

\section{Post-operative course}

One month after the operation the visual acuity was $20 / 20$ on the right eye and 20/10 on the left eye and the visual field defect also improved (figure 1). Three months after the operation she returned to work.

\section{Discussion}

Maitland introduced' the term "chiasmal apoplexy" for sudden retro-orbital or frontal headache associated with abrupt visual loss by acute bleeding in 

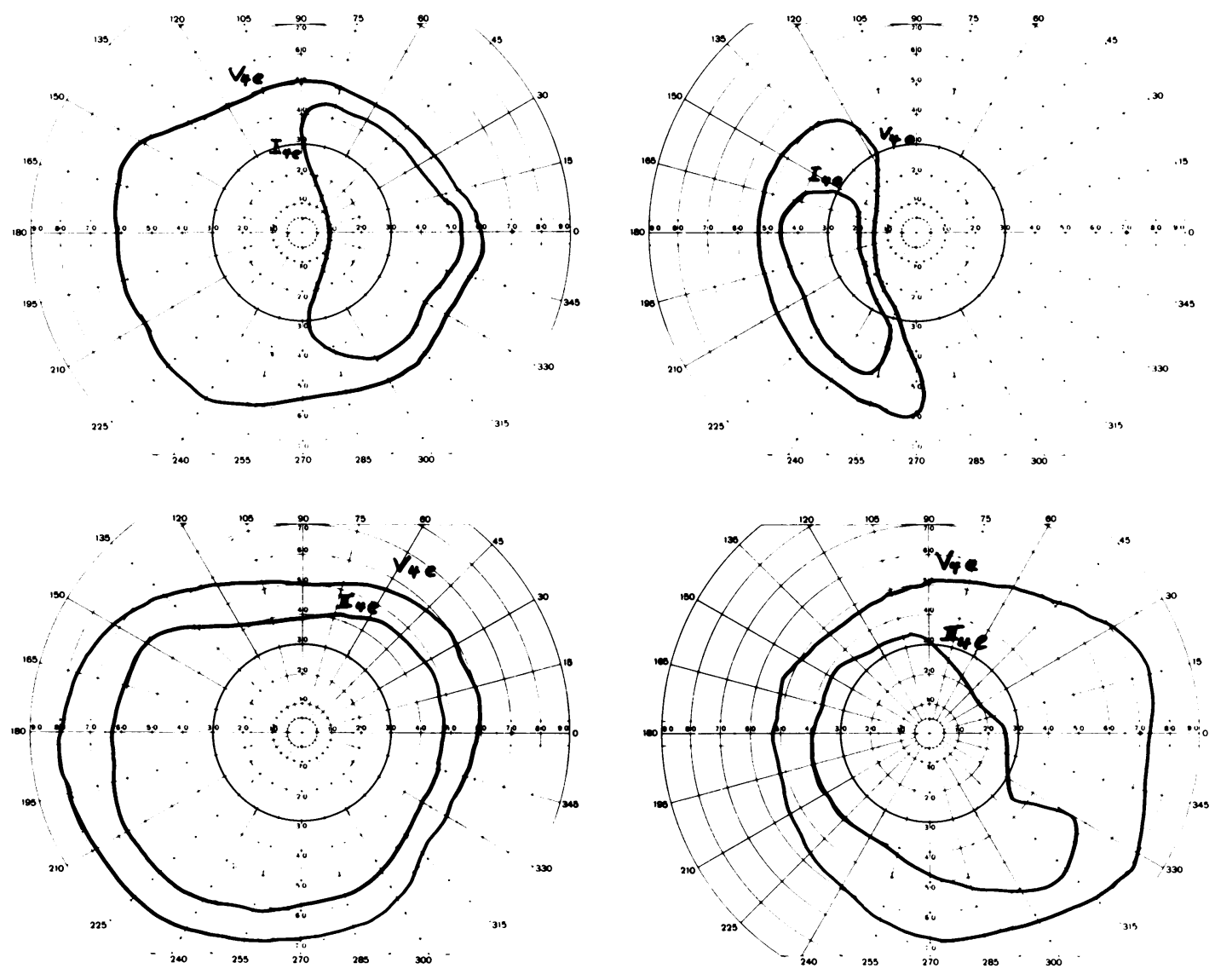

Fig 1 Visual field defect 4 hours after the haemorrhage (upper): bitemporal hemianopia. Visual field defect 3 months after surgery (lower): relative right temporal quadrantanopia.

the optic chiasm. Our case reflects the syndrome's typical triad: (1) abrupt retro-orbital and frontal headache; (2) abrupt loss of visual acuity; (3) visual field defect of chiasmal type.

Sixteen similar cases $^{1-11}$ have been reported in the literature. Females and males were equally affected, mostly during the second and third decade of life. Headache was mostly of sudden onset, retro-orbital, frontal or sometimes temporo-occipital ${ }^{9}$ and was usually the first symptom. Patients typically complained of visual blurring and some temporal visual field defect. They all had diminished visual acuity and visual field defects were either characteristic of a chiasmal lesion (temporal hemianopia or quadrantanopia some associated with scotomas) or of a junctional defect. Palor of the optic disc and relative afferent pupillary defect were often found.

Four patients had xanthochromic CSF indicating bleeding into the subarachnoid space ${ }^{15912}$ and two became stuporose. ${ }^{912}$ Recurrent haemorrhage was clearly established in three patients. ${ }^{3689}$ One experienced five acute episodes over a period of four years.

Only the present case was investigated with MRI, the most sensitive and specific imaging method for cavernous malformations of the CNS. ${ }^{15}$ The coronal and sagittal slices on MRI clearly showed enlargement of the optic chiasm, predominantly on the right side (figs 3 and 4). Three days after the haemorrhage, the mixed hypo- and slightly hyperintense signals (compared with the grey matter), on Tl- and protonweighted images suggested an acute haemorrhage. The lack of evidence of either tumour parenchyma or peritumoural oedema was suggestive of vascular malformation. ${ }^{12}$ There are few reports of MRI with lesions of the chiasm. ${ }^{1314}$ In one report a haemorrhage into the chiasm was secondary to chiasmal glioma. ${ }^{13}$ 

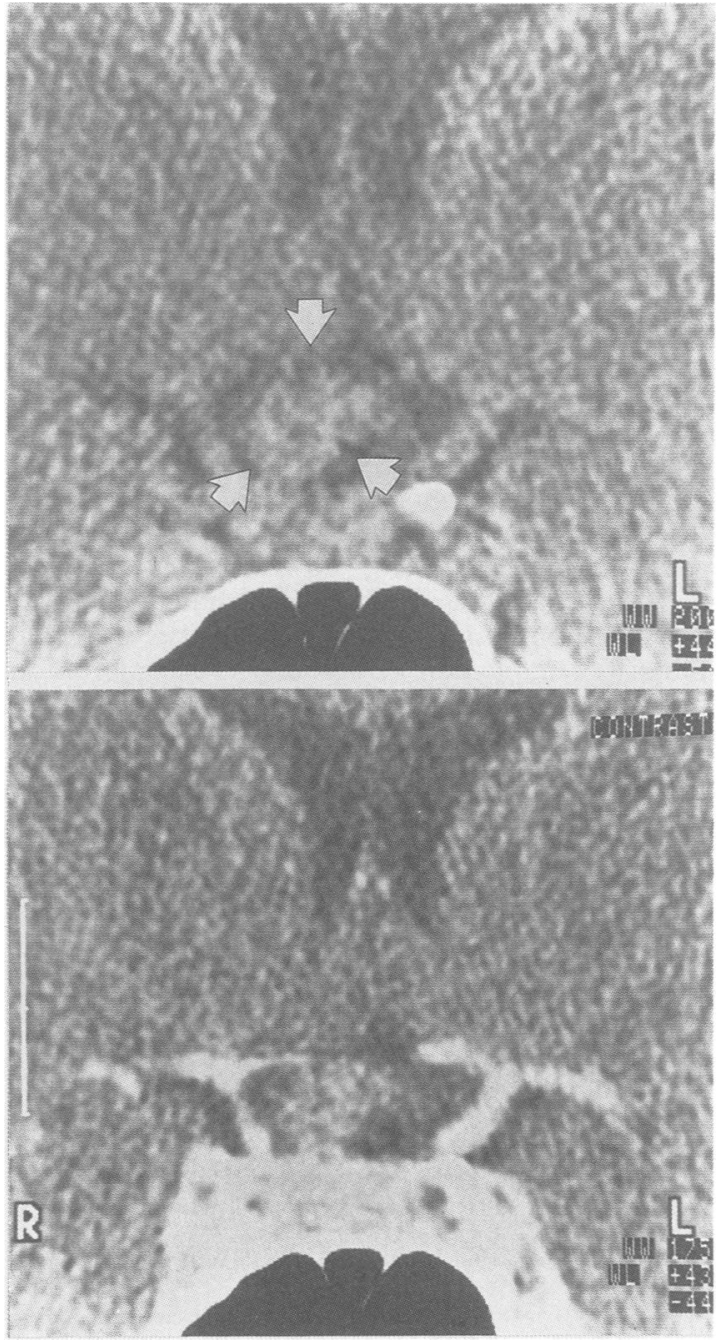

Fig 2 One day after haemorrhage (coronal section): highdensity, poorly enhancing, mass in the right optochiasmal cistern (upper: unenhanced; lower: enhanced).

CT scans were performed in $14^{1568-11}$ of the 17 reviewed cases of chiasmal apoplexy. All showed a high-density, variably enhancing, mass in the suprasellar region. Subarachnoid haemorrhage was not seen. Carotid angiography (17 patients) demonstrated no vascular abnormalities except for an ectatic vein near the chiasm in one, ${ }^{1}$ a vascular density in the suprasellar region in another ${ }^{9}$ and a suprasellar mass in 3 cases. ${ }^{810}$ Angiography remains essential to exclude an aneurysm.

Vascular malformations are commonly divided into five types: telangiectasias, varix, arteriovenous malformation (AVM), venous malformation, cavernous mal-

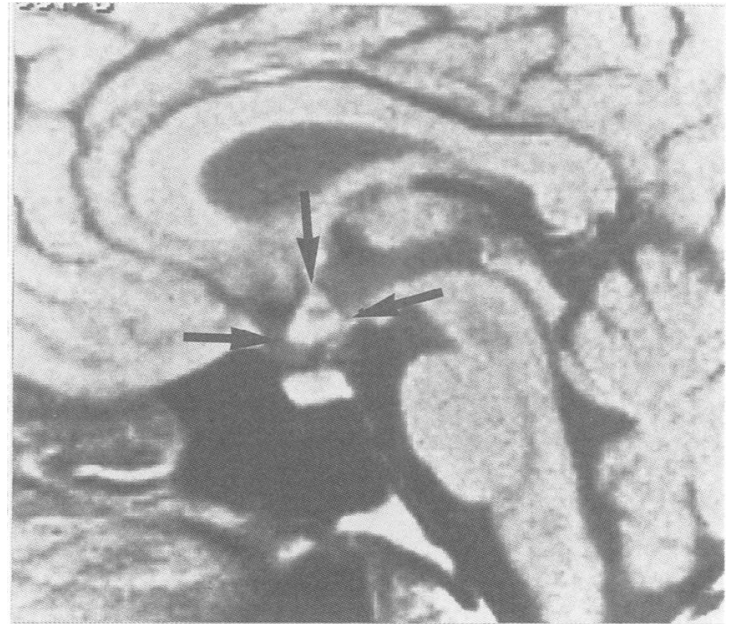

Fig 3 MRI three days after haemorrhage (sagittal section), mildly $T$-WI (TR:500/TE:40): enlargment of the optic chiasm (arrows) by an acute intrachiasmal haematoma with mild peripheral hyperintensity and central hypointensity (compared with grey matter).

formation. ${ }^{16}{ }^{17}$ Cavernous malformations are characterised by large sinusoidal vascular spaces which are not separated by parenchyma. The walls of these dilated channels are thin with no smooth muscle or elastic tissue and are prone to rupture and lead to severe haemorrhaye. Visual defects caused by intracranial vascular malformations are usually

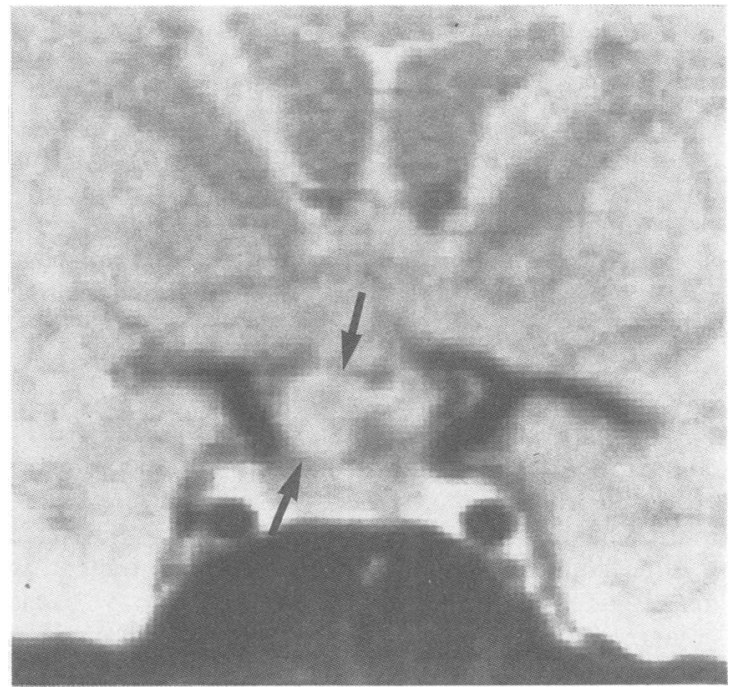

Fig $4 M R I$ three days after haemorrhage (coronal section), proton-WI (TR:2000/TE:40): enlargment of the optic

chiasm (arrows). Mixed hypo- and slight hyperintense signal (compared with grey matter). 


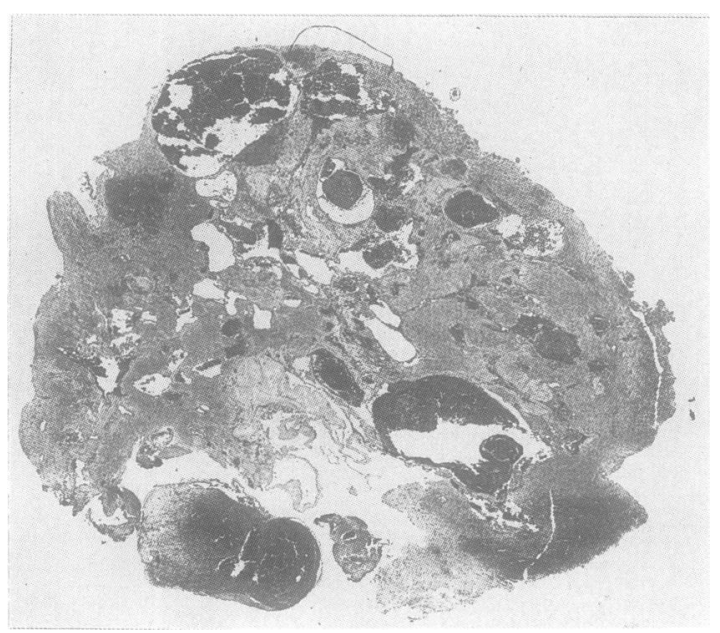

Fig 5 Photomicrograph of the cavernous malformation (6 $\mathrm{mm}$ in diameter). Note the sinusoidal, thin-walled vascular spaces and the partial thromboses. No neural parenchyma is present between the vessels. $H$ and $E$ staining, $\times 25$.

associated with occipital and temporal malformations or with extrinsic compression of the chiasm, optic nerve or tract by such abnormalities.

Of the 17 reported cases, 10 had histological confirmation of an intrachiasmatic vascular malformation, six presented with coagulated or liquefied blood in a cyst but were thought to have a vascular malformation that was destroyed by the haemorrhage and one was a haemangioendothelioma. Of the 10 malformations, four were AVMs, two were venous angiomas and four were cavernous angiomas.

The differential diagnosis of an abrupt "chiasmal syndrome" includes: 1) ischaemic, 2) haemorrhagic, 3) ischaemic and haemorrhagic and 4) demyelinating diseases. Ischaemia may originate from extrinsic compression by adjacent structures. Surrounding tumours like meningiomas, craniopharyngiomas, suprasellar cysts $^{20}$ (epidermoid, arachnoid) or dolichoectatic arteries can impinge on chiasmal perfusion. Arteriosclerotic occlusion ${ }^{21}$ and cranial arteritis also may reduce the blood supply. Haemorrhage may be classified as intrachiasmatic and perichiasmatic. Intrachiasmatic vascular malformations and neoplasms, especially gliomas, ${ }^{123}$ are a major cause of intrachiasmatic haemorrhage. Perichiasmatic haemorrhage results from intrasellar and anterior communicating artery aneurysms. Partial thrombosis may cause enlargement of an unruptured aneurysm and result in an acute chiasmal syndrome. ${ }^{22}$ Pituitary apoplexy, ${ }^{23}$ certainly the most challenging differential diagnosis, combines ischaemia and haemorrhage and presents with sudden headache, meningeal irritation, ophthalmoplegia, visual loss and altered consciousness.
Demyelinating chiasmal lesions are described in patients with multiple sclerosis. ${ }^{23}$

All patients reported underwent a frontal, frontotemporal or fronto-parietal craniotomy. One patient had a transphenoidal pituitary exploration for suspected pituitary apoplexy and then had a frontal craniotomy. ${ }^{10}$

The chiasm, the adjacent optic tract or nerve were all clearly swollen by a haematoma or a cystic lesion containing old blood. After incision, distention of the nerve was less and visual deficit improved in 11 of the 16 patients. We think that surgical decompression is most effective if done early.

We conclude that "chiasmal apoplexy" due to acute intrachiasmatic haemorrhage produces a characteristic clinical picture (headache, diminished visual acuity and visual field defect). CT-scan can identify a haemorrhage in the optic chiasm, but the superior specificity and sensitivity of MRI makes it a more powerful examination. Rapid surgical decompression, with excision of the vascular malformation to avoid recurrence, may improve or even restore vision.

We thank Dr Antoine Uske for the radiological images and Dr Judith Miklossy for the pathological material.

\section{References}

1 Maitland CG, Abiko S, Hoyt WF, Wilson CB, Okamura T. Chiasmal apoplexy. Report of four cases. J Neurosurg 1982; 56:118-22.

2 Uihlein A, Rucker W. The neurosurgeon's role in acute visual failure. AMA Arch Ophtal 1958;60:223-9.

3 Holt H. Cysts of the intracranial portion of the optic nerve. Am J Ophthalmology 1966;61:1166-70.

4 Riishede J, Seedorff HH. Spontaneous haematoma of the optic chiasma. Report of a case. Acta Ophthalmologica 1974;52 317-22.

5 Fermaglich J, Kattah J, Manz H. Venous angioma of the optic chiasm. Ann Neurol 1978;4:470-1.

6 Roski RA, Gardner JH, Spezler RF. Intrachiasmatic arteriovenous malformation. Case report. J Neurosurg 1981;54:540-1.

7 Carter JE, Wymore J, Ansbacher L, Reid WS. Sudden visual loss and chiasmal syndrome due to an intrachiasmatic vascular malformation. J Clin Neuro Ophthalmol 1982;2:163-7.

8 Lavin PJM, McCrary JA, Roessmann U, Ellenberger C. Chiasmal apoplexy: Haemorrhage from a cryptic vascular malformation in the optic chiasm. Neurology 1984;34:1007-11.

9 Mohr G, Hardy J, Gauvin P. Chiasmal apoplexy due to ruptured cavernous haemangioma of the optic chiasm. Surg Neurol 1985; 24:636-40.

10 Reilly PL, Oatey PE. Optic nerve apoplexy. Report of two cases. $J$ Neurosurg 1986;64:313-6.

11 Nobuhiko M, Yuzo Y, Masaki S. Cavernous haemangioma of the optic nerve. Case report. J Neurosurg 1988;69:292-4.

12 Gomori JM, Grossman RI. Head and neck haemorrhage. In: Kressel Y. Magnetic Resonance Annual 1987. New York: Raven Press, 1987:71-112.

13 Albert A, Lee BC, Saint-Louis L, Deck MD. MRI of optic chiasma and optic pathways. AJNR 1986;7:255-8.

14 Daniels DL, Herfkins R, Gager WE, Meyer GA, Koehler PR, Williams AL, Haughton VM. Magnetic resonance imaging of the optic nerves and chiasm. Radiology 1984;152:79-83. 
15 Rigamonti D, Drayer BP, Johnson PC, Hadley MN, Zabramski J, Spetzler RF. The MRI appearance of cavernous malformations (angiomas). J Neurosurg 1987;67:518-24.

16 McCormick WF. The pathology of vascular ("arteriovenous") malformations. J Neurosurg 1966;24:807-16.

17 Russel DS, Rubinstein LJ. Pathology of tumours of the nervous system, ed 4. Baltimore: Williams and Wilkins, 1977: 116-45.

18 Brühlmann $Y$, De Tribolet N, Berney J. Les angiomes caverneux intracérébraux. Neurochirurgie 1985;31:271-9.

19 Simard JM, Garcia-Bengochea F, Ballinger WE, Mickle JP, Quisling RG. Cavernous angioma: A review of 126 collected and 12 new clinical cases. Neurosurgery 1986;18:162-70.

20 Schneider RC, Kriss FC, Falls HF. Prechiasmal infarction associated with intrachiasmal and suprasellar tumours. $J$ Neurosurg 1970;32:197-207.
21 Glaser JS. Vascular-compressive lesions. In: Glaser JS. Neurophthalmology. Maryland: Harper and Row, 1978: 122-3.

22 Nobuhiko A. Partially thrombosed aneurysm presenting as the sudden onset of bitemporal hemianopsia. Neurosurgery 1988; 22:564-6.

23 Spector RH, Glaser JS, Schatz N. Demyelinative chiasmal lesions. Arch Neurol 1980;37:757-62.

\section{Addendum}

A cavernous angioma of the optic tract investigated by MRI has been reported in the mean time: Zentner J, Grood W, Hassler W. Cavernous angioma of the optic tract. J Neurol 1989;236:117-9. 